\title{
Prevalence of hepatitis $C$ infection, screening and associated factors among men who have sex with men attending gay venues: a cross-sectional survey (PREVAGAY), France, 2015
}

\author{
Sophie Vaux ${ }^{1 *}$ (D), Stéphane Chevaliez ${ }^{2,3}$, Leïla Saboni ${ }^{1}$, Claire Sauvage ${ }^{1}$, Cécile Sommen ${ }^{1}$, Francis Barin ${ }^{4}$,
} Antonio Alexandre ${ }^{5}$, Marie Jauffret-Roustide ${ }^{1,6}$, Florence Lot ${ }^{1}$, Annie Velter ${ }^{1}$, for the ANRS-Prevagay group

\begin{abstract}
Background: Over the last 20 years, Hepatitis C virus (HCV) infection prevalence has dramatically increased among HIV-infected men who have sex with men (MSM) in many countries worldwide. It is suspected that this increase is primarily driven by sexual behaviours linked to blood exposure. Monitoring these behaviours is crucial to understand the drivers of the epidemic. This study assessed the prevalence of chronic HCV infection among MSM attending gay venues and associated chronic HCV risk factors. HCV screening and associated factors were described.

Methods: The cross-sectional survey PREVAGAY, based on time-location sampling, was conducted in 2015 among MSM attending gay venues in 5 French metropolitan cities. A self-administered questionnaire was completed and capillary whole blood on dried blood spots (DBS) collected. Possible factors associated with chronic HCV prevalence and with HCV screening in the previous year were investigated using Poisson regression.

Results: Chronic HCV infection prevalence from DBS analysis was 0.7\% [IC95\%: 0.3-1.5] in the study's 2645 participants and was 3.0\% [1.5-5.8] in HIV-positive MSM. It was significantly higher in those who reported the following: (lifetime) slamming (with or without the sharing of injection equipment); (during the previous year) fisting and chemsex, unprotected anal intercourse with casual partners, using gay websites and/or of mobile-based GPS applications, and having more than 10 sexual partners.

Only 41.3\% [38.2-44.5] of the participants reported HCV screening during the previous year. Screening was significantly more frequent in MSM under 30 years of age, those who were HIV-positive, those vaccinated against hepatitis $B$ and meningococcus $C$, and those who reported the following (during the previous year): more than 10 sexual partners, at least one sexually transmitted infection and fisting.

(Continued on next page)
\end{abstract}

\footnotetext{
* Correspondence: sophie.vaux@santepubliquefrance.fr

${ }^{1}$ Department of Infectious Diseases - Santé publique France, French national

public health agency, 12 rue du Val d'Osne, 94415 Saint-Maurice, Cedex,

France

Full list of author information is available at the end of the article
}

(c) The Author(s). 2019 Open Access This article is distributed under the terms of the Creative Commons Attribution 4.0 International License (http://creativecommons.org/licenses/by/4.0/), which permits unrestricted use, distribution, and reproduction in any medium, provided you give appropriate credit to the original author(s) and the source, provide a link to the Creative Commons license, and indicate if changes were made. The Creative Commons Public Domain Dedication waiver (http://creativecommons.org/publicdomain/zero/1.0/) applies to the data made available in this article, unless otherwise stated. 


\begin{abstract}
(Continued from previous page)
Conclusion: Chronic HCV infection prevalence in MSM attending gay venues was significantly higher in HIVpositive MSM and in those with risky sexual behaviours. Reflecting current screening recommendations for specific populations, previous HCV screening was more frequent in HIV-positive individuals and those with risky sexual behaviours. Nevertheless, HCV screening coverage needs to be improved in these populations. Comprehensive medical management, which combines screening and linkage to care with prevention strategies, is essential to control HCV among MSM.
\end{abstract}

Keywords: Men who have sex with men, Hepatitis C virus infection, Prevalence, Time-location sampling, Screening, HIV/HCV co-infection

\section{Background}

Over the last 20 years, the HCV epidemic has dramatically increased in HIV-positive men who have sex with men (MSM) in the US, Asia, Australia and Europe [1-3]. It is suspected that this increase is driven by greater exposure to contaminated blood during risky sexual behaviours including unprotected anal intercourse (UAI), fisting (brachioproctic insertion), chemsex (recreational drug use before or during sex) and having a high number of sexual partners $[4,5]$. A study which performed a phylogenetic analysis using data from five countries (England, the Netherlands, France, Germany and Australia) revealed the presence of international clusters among HIV-positive MSM [3]. Monitoring risky sexual behaviours in MSM is therefore crucial to better understand the drivers of $\mathrm{HCV}$ transmission, and to plan and evaluate prevention interventions.

France is a low endemic country for HCV infection. In 2004, the prevalence of anti-HCV antibodies in the general population was $0.84 \%$ (CI95\% [0.65-1.10]). In men and MSM, it was estimated at $0.66 \%$ [CI95\%: 0.45-0.96] and $0.39 \%$ [CI95\%: 0.06-2.56], respectively. The prevalence of chronic HCV infection (i.e., HCV RNA +) was estimated at $0.53 \%$ [C195\%: 0.4-0.7] in the general population, with $43 \%$ being unaware of their infection [6]. Chronic HCV prevalence tended to decrease over the following years with models estimating $0.42 \%$ in the general population in 2011 [7]. In 2009, the Prevagay study estimated, for the first time, HIV seroprevalence in MSM attending gay venues in Paris (17.7\% [C195\%: 15.3-20.4]) [8]. It also estimated HCV seroprevalence (HCV antibodies) (1.02 [CI95\%: 0.34-1.66]), which tended to be higher among HIV-positive MSM (1.9\%) than their HIV-negative counterparts (0.8\%). Updating $\mathrm{HCV}$ prevalence data in MSM in France is necessary to describe and understand the evolution of the epidemic and the drivers of HCV transmission.

The WHO's (World Health Organization) goal is to eliminate viral hepatitis worldwide by 2030 [9]. France hopes to eliminate it by 2025. Since 2014, several direct-acting antiviral (DAA) drugs with excellent effectiveness against hepatitis $C$ have been approved worldwide.
Safe and well-tolerated combinations of these drugs yield very high rates of sustained virological response (over 95\%) $[10,11]$.

$\mathrm{HCV}$ screening is a key element of the HCV care continuum. It allows the prompt diagnosis and treatment of patients who test positive and helps them achieve viral suppression. Because of the increased risk of $\mathrm{HCV}$ infection in HIV-positive MSM, international and French guidelines recommend screening for $\mathrm{HCV}$ in this population [12-16]. Despite the importance of screening, rates of HCV screening uptake are poorly documented. The levers and barriers to screening uptake need to be investigated in greater detail in order to guide to guide decision making on the prevention actions to implement

In 2015, Santé publique France, the French national public health agency, conducted a new Prevagay study (Prevagay 2015) in MSM attending gay venues in Paris and 4 other French metropolitan cities in order to update HIV prevalence estimations through improved representativeness of this population and more precise estimators. The additional objectives of this study were to estimate $\mathrm{HBV}$ and $\mathrm{HCV}$ prevalences and to describe $\mathrm{HCV}$ screening in this population. The methodology of this study and the HIV and HBV prevalences values have already been published [17-19].

The present study aimed to assess the prevalence of chronic HCV infection in MSM attending gay venues and associated risk factors, and to describe $\mathrm{HCV}$ genotypes. It also aimed to describe HCV screening in this population and associated factors.

\section{Methods}

\section{Survey design and participants}

Prevagay 2015 is an anonymous cross-sectional study, using two-stage time-location sampling (TLS). TLS, also called time-space sampling or venue-based sampling, is widely used to collect data from hard-to-reach populations who frequent known locations [20]. It is widely used in surveys on MSM. The principle is to recruit individuals in physical places at times when they gather there (e.g. gay bars, clubs, backrooms) [21, 22]. 
Prevagay 2015 was conducted between September and December 2015 in MSM attending commercial gay venues in five French metropolitan cities (Lille, Lyon, Montpellier, Nice and Paris). The choice of these cities was based both on feasibility constraints and on epidemiological criteria. A minimum number of sufficiently frequented accessible venues was needed. Because updating HIV prevalence estimations was the main objective of this study, we chose cities with different HIV epidemiological profiles based on the number of new HIV diagnoses in MSM (French regional HIV monitoring data), the number of HIV prevalence declarations (Gay and Lesbian press survey 2011), and regional alerts of increasing numbers of STI [19]. In each city, the expected sample size was evaluated using the expected HIV prevalence and the desired precision of estimates. Two types of gay venues were investigated: bars (without sex) and backrooms or saunas (where sex was possible).

During the first stage in each city, we used simple random venue-day-time sampling without replacement, with a minimum of one visit per venue. In the second stage, for each venue-day-time, MSM were selected using systematic random sampling.

A team of investigators was created for each city, led by a local staff member from the association 'Equipe Nationale d'Intervention en Prévention et Santé pour les Entreprises' (ENIPSE). Among other activities, this association organises disease prevention interventions in gay venues. During visits, each team recruited participants using flyers and information letters about the survey. They also estimated the number of eligible attendees during the visit and noted the number of refusals to participate in the survey. A form collecting basic sociodemographic information was offered to MSM who refused to participate.

Men at least 18 years old, who had had sex with other men in the previous year, who were able to read and speak French, and who agreed to both perform finger-prick blood self-sampling and answer an anonymous self-administered questionnaire were eligible. Electronic tablets were used for the questionnaire and missing answers were not permitted. Test results were not given to participants but they did receive a prevention kit including condoms and flyers indicating the nearest screening centre.

The methodology is described in greater detail elsewhere [19].

\section{Study questionnaire}

The following variables were recorded: sociodemographic characteristics, previous screening tests for HIV and HCV (response: yes, no, I don't know) and the results of these tests, sexually transmitted infection (STI) history (including gonorrhoea, syphilis, chlamydia and
Lymphogranuloma venereum, genital warts) during the previous year, sexual behaviours in the previous year including the number of male partners and UAI with casual partners, alcohol and psychoactive drugs' consumption during the previous year, as well as lifetime slamming practices, and previous vaccinations against hepatitis B and meningococcal C (response: yes, no, I don't know). Venue attendance frequency was recorded by asking participants how many times they had visited the venue included in the sampling frame in the previous month.

\section{Laboratory testing}

$\mathrm{HCV}$ and HBV testing were performed by the National Reference Laboratory (NRL) for Viral Hepatitis B, C and delta (based in Creteil, France) using capillary whole blood collected on dried blood spots (DBS). The protocol used for HCV antibodies and hepatitis B surface antigen (HBsAg) detection is described elsewhere [23].

Briefly, total HCV antibodies were measured from DBS using an automated third-generation enzyme immunoassay (EIA; aHCV Vitros ECi; Ortho-Clinical Diagnostics, Raritan, New Jersey). On the basis of ROC curve analysis, the optimal cut-off ratio was estimated at 0.6. Samples with ratio values above the cut-off were considered positive.

In seropositive samples, HCV RNA level was tested for using the Abbott RealTime HCV assay (Abbott Molecular, Des Plaines, Illinois). In samples containing at least $2.5 \mathrm{Log} \mathrm{IU} / \mathrm{mL}$ of HCV RNA, HCV genotype and subtype were determined by directly sequencing a portion of the NS5B gene encoding the RNA-dependent RNA polymerase, followed by phylogenetic analysis, as described elsewhere [24].

HBsAg detection was carried out by means of a one-step manual EIA (Monolisa ${ }^{\mathrm{m}}$ HBs Ag ULTRA, BIO-RAD, Marnes-la-Coquette, France). On the basis of ROC curve analysis, the optimal cut-off value was established at 13.6.

HIV testing was performed by the French NRL for HIV (Tours, France) with a combined immunoassay for detection of both p24 antigen and HIV antibodies (Genscreen ultra HIV Ag-Ab; Biorad), as described elsewhere [8]. All anti-HIV positive samples were confirmed by serotyping and/or western blot [25].

\section{Data analysis}

To make inferences from the random sample to the MSM population frequenting gay venues, a sampling weight was assigned to each participant. The generalized weight share method [26] was used in analyses, taking into account the frequency of venue attendance. More details are provided elsewhere [19]. 
We estimated the prevalence of biological chronic $\mathrm{HCV}$ infection (anti-HCV antibodies + and $\mathrm{HCV}$ RNA + ). We also estimated the prevalence of $\mathrm{HCV}$ screening during the previous year.

Participants who reported consuming GHB, mephedrone or crystal methamphetamine during or just before sex were considered to have practiced chemsex [27]. Participants reporting injection of psychoactive drugs during sexual encounters were considered to have practiced slamming.

The following possible associations with chronic $\mathrm{HCV}$ infection and HCV screening within the previous year were investigated using univariate and multivariable Poisson regression: city, place of residence, size of the city of residence, age in years $(18-29,30-44,45$ and over), place of birth, financial situation ("Comfortable Getting by" vs. "Struggling - Soon to be in debt"), sexual identity (homosexual, bisexual, other), HIV status (diagnosed HIV-infected, HIV-infected but not diagnosed, HIV-negative). In addition, the following possible associations were also investigated, with respect to the previous year: attending bars, saunas, backrooms and outdoor meeting places, use of gay dating websites or mobile-based GPS applications, UAI with casual partners, more than 10 sexual partners, at least one STI, consumption of alcohol (more than 6 glasses per day), BDSM (bondage, discipline, sadism and masochism), fisting and chemsex; and finally, with respect to one's lifetime, slamming (with or without the sharing of injection equipment). Vaccinations against hepatitis $\mathrm{B}$ and meningococcus $\mathrm{C}$ (declarative data) were also investigated for HCV screening.

Only explanatory variables associated with the outcome at a $P$-value of $<0.1$ in univariate analyses were eligible for the multivariable models and are listed in the results. Final multivariable models were built using backward elimination. Only variables with a $P$-value $<0.05$ were kept in the final multivariable models. The prevalence ratio (PR), adjusted prevalence ratio (PRa) and 95\% confidence intervals (95\% CI) are presented in the results section. In all analyses (univariate and multivariable) a two-sided $p$-value $<0.05$ was considered significant. Collinearity between variables was tested for. To assess whether any variables in the final model were subject to confounding by variables omitted from the final model, each omitted variable was re-introduced individually. Data analyses were performed using Stata 12.2 (StataCorp, USA).

\section{Results}

\section{Profile of participants}

Among the 5324 men invited to participate, 2646 agreed to do so. One blood sample was not usable for HCV analysis. Exploitable data (i.e., both a blood sample and a self-administered questionnaire) were therefore available for 2645 individuals in the five cities included (participation rate: 50\%): 478 (80\%) in Lille, 485 (48\%) in Lyon, 266 (50\%) in Montpellier, 328 (50\%) in Nice and 1088 (46\%) in Paris. Respondent profiles according to city are described elsewhere [19].

Twenty-one percent of non-participants agreed to complete a refusal questionnaire. Their median age was 42 years and they reported being HIV positive less frequently than participants $(10 \%)$.

The majority of participants were recruited in backrooms or saunas (61.8\% [C195\%: 54.0-69.0]). Median age was 41 years (mean: 40.6 years; range: $18-80$ years), $64.3 \%$ [60.6-67.8] had a university degree, $82.9 \%$ [80.385.3] were born in France, 83.6\% [80.8-86.0] defined themselves as homosexual, $12.8 \%$ [10.8-15.2] bisexual, $0.8 \%$ [0.4-1.8] heterosexual while 2.8\% [1.9-4.0] refused to define themselves in relation to their sexuality. With respect to sexual behaviours in the previous year, $41.8 \%$ [38.8-45.0] reported UAI with casual partners, 44.9\% [41.3-48.6] had had more than 10 sexual partners (11.4\% [9.6-13.6] more than 50 in the previous year), $11.2 \%$ [9.2-13.6] reported BDSM, and 16.7\% [14.6-19.0] fisting with at least one casual partner. Twelve percent (12.6\%) reported chemsex during the previous year [10.8-14.7]. Slamming during one's lifetime was reported by $3.1 \%$ [2.2-4.3] and $0.5 \%$ [0.3-0.9] declared sharing syringes/needles during slamming (Table 1). HIV prevalence was 14.3\% [CI95\%: 12.0-17.0] among participants while HBV infection prevalence was 0.6\% [C195\%: $0.3-$ 1.3].

With regard to vaccinations, 63.0\% [59.9-65.9] of the participants declared they were vaccinated against hepatitis B and 14.4\% [12.6-16.3] against meningococcus C.

\section{Hepatitis C prevalence}

Among the 2645 participants, 26 MSM tested positive for anti-HCV antibodies and for HCV RNA. Chronic $\mathrm{HCV}$ prevalence (anti-HCV antibodies + and HCV RNA +) was 0.7\% [0.3-1.5]. In HIV-positive and HIV-negative MSM, chronic HCV prevalence was 3.0\% [1.5-5.8] and $0.3 \%$ [0.1-1.6], respectively. Among all chronically HCV infected MSM, an estimated 59.6\% [21.0-89.1] were co-infected with HIV. No HBV coinfection was identified in MSM with chronic HCV. Only 37.1\% [12.8-70.3] of the latter were aware of their HCV status.

Chronic HCV prevalence was 10.6\% [4.5-23.1] for MSM with a history of slamming, and $16.6 \%$ [3.5-52.6] and 9.4\% [3.3-24.1], in MSM who reported lifetime slamming with and without the sharing of injection equipment, respectively (Table 2). Chronic HCV prevalence was 3.5\% [1.8-6.7] in those who reported chemsex in the previous year and $2.9 \%$ [1.1-7.7] in those who reported fisting. It was $1.4 \%[0.6-3.1]$ in MSM who 
Table 1 Characteristics of participants, PREVAGAY 2015, France - weighted data

\begin{tabular}{|c|c|c|c|}
\hline$N=2645$ & $\mathrm{n}$ & $\%$ & [C195\%] \\
\hline \multicolumn{4}{|l|}{ Recruitment establishments } \\
\hline Bars or clubs (without sex) & 1283 & 38.2 & [31.0-46.0] \\
\hline Backroom, saunas (sexual relations possible) & 1362 & 61.8 & [54.0-69.0] \\
\hline \multicolumn{4}{|l|}{ City of inclusion in the survey } \\
\hline Lille & 478 & 12.0 & {$[10.1-14.3]$} \\
\hline Lyon & 485 & 20.5 & {$[16.4-25.3]$} \\
\hline Montpellier & 266 & 4.0 & {$[3.3-4.9]$} \\
\hline Nice & 328 & 14.4 & [11.3-18.2] \\
\hline Paris & 1088 & 49.0 & {$[43.8-54.2]$} \\
\hline \multicolumn{4}{|l|}{ Age } \\
\hline $18-29 y$ & 635 & 24.6 & [20.8-28.8] \\
\hline $30-44$ y & 1043 & 35.3 & [32.4-38.4] \\
\hline $45 \mathrm{y}$ and more & 967 & 40.1 & [35.5-44.9] \\
\hline University degree & 1686 & 64.3 & [60.6-67.8] \\
\hline Born in France & 2285 & 82.9 & [80.3-85.3] \\
\hline \multicolumn{4}{|l|}{ Financial situation: } \\
\hline Comfortable - Getting by & 1861 & 71.3 & [68.5-74.0] \\
\hline Struggling - Soon to be in debt & 784 & 28.7 & {$[26.0-31.5]$} \\
\hline \multicolumn{4}{|l|}{ Place of residence: } \\
\hline France: - Town <20,000 inhab. & 517 & 22.2 & [19.5-25.0] \\
\hline - Town $20,000 \leq \leq 100,000$ inhab. & 506 & 19.4 & [16.9-22.0] \\
\hline - Town > 100,000 inhab. & 1519 & 51.5 & [48.0-54.9] \\
\hline Outside France & 103 & 7.1 & {$[5.3-9.3]$} \\
\hline \multicolumn{4}{|l|}{ Sexual identity: } \\
\hline Homosexual & 2299 & 83.6 & [80.8-86.0] \\
\hline Bisexual or other & 346 & 16.4 & [14.0-19.2] \\
\hline \multicolumn{4}{|l|}{ Attendance of (during the previous year): } \\
\hline Venues where sexual relations are possible (saunas, backrooms, outdoor meeting places) & 2188 & 84.6 & [80.3-88.0] \\
\hline Bars (without sex) & 2247 & 73.1 & {$[68.4-77.4]$} \\
\hline Backrooms & 1395 & 48.8 & [43.6-54.0] \\
\hline Use of gay websites and /or use of mobile-based GPS applications & 1982 & 69.7 & {$[66.0-73.2]$} \\
\hline Outdoor meeting places & 1801 & 31.2 & {$[28.5-34.1]$} \\
\hline UAI with casual partners (during the previous year) & 1168 & 41.8 & {$[38.8-45.0]$} \\
\hline More than 10 sexual partners (during the previous year) & 1278 & 44.9 & [41.3-48.6] \\
\hline At least one STI (during the previous year) & 556 & 17.8 & {$[15.3-20.5]$} \\
\hline \multicolumn{4}{|l|}{$\begin{array}{l}\text { Consumption of (before or during sexual } \\
\text { intercourse, during the previous year): }\end{array}$} \\
\hline $\begin{array}{l}\text { Psychoactive products (cocaine, GBL, GHB, ecstasy, } \\
\text { heroin, amphetamines, crystal methamphetamine } \\
\text { ketamine, crack, mephedrone, cathinones) }\end{array}$ & 706 & 20.8 & {$[18.2-23.8]$} \\
\hline Alcohol (more than 6 glasses) & 1753 & 58.3 & {$[54.1-62.3]$} \\
\hline Chemsex (during the previous year) & 449 & 12.6 & {$[10.8-14.7]$} \\
\hline \multicolumn{4}{|l|}{ Slamming (lifetime) } \\
\hline Yes, without sharing injection equipment & 73 & 2.5 & {$[1.7-3.7]$} \\
\hline Yes and sharing injection equipment & 24 & 0.5 & {$[0.3-0.9]$} \\
\hline
\end{tabular}


Table 1 Characteristics of participants, PREVAGAY 2015, France - weighted data (Continued)

\begin{tabular}{|c|c|c|c|}
\hline$N=2645$ & $n$ & $\%$ & [Cl95\%] \\
\hline No & 2548 & 97.0 & {$[95.7-97.8]$} \\
\hline \multicolumn{4}{|c|}{ Sexual Practices with casual partners (during the previous year) } \\
\hline BDSM & 360 & 11.2 & {$[9.2-13.6]$} \\
\hline Fisting & 464 & 16.7 & [14.6-19.0] \\
\hline \multicolumn{4}{|c|}{ Hepatitis B vaccination (self-declared) } \\
\hline Yes & 1735 & 63.0 & [59.9-65.9] \\
\hline No & 564 & 22.2 & [19.7-25.0] \\
\hline Did not know & 346 & 14.9 & {$[12.6-17.4]$} \\
\hline \multicolumn{4}{|c|}{ Meningococcus $C$ vaccination (self-declared) } \\
\hline Yes & 446 & 14.4 & [12.6-16.3] \\
\hline No & 1041 & 40.3 & [37.3-43.4] \\
\hline Did not know & 1158 & 45.3 & [42.3-48.4] \\
\hline \multicolumn{4}{|l|}{ HCV status ${ }^{\text {a) }}$} \\
\hline $\mathrm{HCV}+$ diagnosed & 12 & 0.3 & {$[0.1-0.6]$} \\
\hline $\mathrm{HCV}+$ undiagnosed & 14 & 0.5 & {$[0.2-1.3]$} \\
\hline HCV - & 2619 & 99.3 & [98.5-99.7] \\
\hline \multicolumn{4}{|l|}{ HIV status ${ }^{\text {a) }}$} \\
\hline HIV + diagnosed & 400 & 13.1 & [10.9-15.7] \\
\hline HIV + undiagnosed & 33 & 1.2 & {$[0.7-2.0]$} \\
\hline HIV - & 2212 & 85.7 & [83.1-88.0] \\
\hline
\end{tabular}

reported more than 10 sexual partners during the previous year and 3.9\% [1.4-10.5] in MSM who reported more than 50 . In those aged 18-29, 30-44 and over 45 years old, respectively, it was $0.3 \%$ [0.07-1.7], $1.2 \%$ [0.4-3.5] and $0.5 \%$ [0.2-1.3].

In multivariable analysis (Table 2), chronic HCV prevalence was significantly higher in MSM who lived in medium-sized towns (from 20,000 to 100,000 inhabitants) than in those living in small towns $(<20,000$ inhabitants) ( $\mathrm{PRa}=16.1$ [2.4-106.8], $p=0.004)$, those born outside France $(\mathrm{PRa}=10.5[3.8-28.9], p=0.001)$, those who reported UAI with casual partners $(\mathrm{PRa}=11.0$ [1.3-95.0], $p=0.03$ ), those who used gay websites and/or mobile-based GPS application ( $\mathrm{PRa}=5.2$ [1.0-27.9], $p<0.05)$, those who reported more than 10 sexual partners in the previous year $(\mathrm{PRa}=3.6$ [1.1-12.3], $p=0.04)$, those who reported lifetime slamming (with or without the sharing of injection equipment) ( $\mathrm{PRa}=3.8$ [1.5-9.7], $p=0.006$ and $\mathrm{PRa}=6.0$ [1.6-23.3], $p=$ 0.009 respectively), those who practiced fisting $(\mathrm{PRa}=$ $5.3[2.0-14.0], p=0.001)$ and those who practiced chemsex ( $\mathrm{PRa}=3.8$ [1.1-12.6], $p=0.03)$ (both during the previous year). Chronic $\mathrm{HCV}$ prevalence was also significantly higher in HIV-infected MSM aware of their HIV status (HIV + diagnosed) $(\mathrm{PRa}=4.5 \quad[1.1-$
18.5], $p=0.04)$. Chronic HCV prevalence was significantly lower in MSM who reported consuming alcohol before or during sexual intercourse during the previous year $(\mathrm{PRa}=0.3[0.1-0.8], p=0.02)$ and in MSM reporting $\mathrm{HCV}$ screening during the previous year $(\mathrm{PRa}=0.2[0.5-0.6], p=0.006)$.

The genotype was determined from $15 \mathrm{HCV}$ RNA positive samples. They were distributed as follows (crude numbers): genotype $4 \mathrm{~d}(n=9)$, genotype 1a $(n=5)$, genotype $3 \mathrm{a}(n=1)$. In the remaining $11 \mathrm{HCV}$ RNA-positive MSM, the HCV RNA level was too low (< $2.5 \mathrm{Log} \mathrm{IU} / \mathrm{mL}$ ) for amplification of the NS5B-coding region.

\section{HCV screening}

Over 40\% (41.3\% [CI95\%: 38.2-44.5]) of the participants reported HCV screening during the previous year, 29.4\% [26.6-32.4] more than 1 year before the study, while 22.3\% [19.6-25.2] reported no screening during their lifetime. Seven percent [5.6-8.6] did not know whether they had ever been screened or not. Therefore, $70.7 \%$ [67.8-73.6] of the participants reported HCV screening at least once in their life.

Fifty percent (50.1\%) [45.3-54.9] of the MSM who reported more than 10 sexual partners during the previous 
Table 2 Characteristics of chronic HCV-infected MSM and associated factors, Prevagay 2015, France - weighted data

\begin{tabular}{|c|c|c|c|c|c|c|c|c|c|}
\hline & \multicolumn{3}{|c|}{ Prevalence $^{\text {a) }}$} & \multicolumn{3}{|c|}{ Univariate analysis } & \multicolumn{3}{|c|}{ Multivariable analysis } \\
\hline & $\mathrm{n}$ & $\%$ & [C195\%] & PR & [C195\%] & $\mathrm{p}$ & PRa & [Cl95\%] & $p$ \\
\hline All $(N=2645)$ & 26 & 0.7 & {$[0.3-1.5]$} & & & & & & \\
\hline \multicolumn{10}{|l|}{ City } \\
\hline Lille & 6 & 0.4 & {$[0.1-1.1]$} & ref. & & & & & \\
\hline Lyon & 3 & 0.5 & {$[0.08-3.0]$} & 1.1 & {$[0.1-8.4]$} & 0.9 & & & \\
\hline Montpellier & 3 & 0.3 & {$[0.05-1.3]$} & 0.6 & {$[0.1-3.8]$} & 0.6 & & & \\
\hline Nice & 6 & 1.0 & {$[0.3-1.9]$} & 2.3 & {$[0.6-9.1]$} & 0.3 & & & \\
\hline Paris & 8 & 0.8 & {$[0.3-1.5]$} & 1.9 & {$[0.4-7.8]$} & 0.4 & & & \\
\hline \multicolumn{10}{|l|}{ Place of birth } \\
\hline France & 21 & 0.5 & {$[0.2-1.0]$} & ref. & & & ref. & & \\
\hline Outside France & 5 & 1.8 & {$[0.4-7.3]$} & 3.6 & {$[0.7-18.0]$} & 0.1 & 10.5 & {$[3.8-28.9]$} & 0.001 \\
\hline
\end{tabular}

Place of residence

France:

\begin{tabular}{|c|c|c|c|c|c|c|c|c|c|}
\hline - Town <20,000 inhab. & 3 & 0.06 & {$[0.01-0.2]$} & ref. & & & ref. & & \\
\hline - Town $20,000 \leq \leq 100,000$ inhab. & 8 & 1.5 & {$[0.3-6.5]$} & 27.2 & [3.3-222] & 0.002 & 16.1 & {$[2.4-106.8]$} & 0.004 \\
\hline$w n>100,000$ inhab. & 14 & 0.8 & {$[0.4-1.6]$} & 13.7 & {$[2.6-71.3]$} & 0.002 & 4.7 & {$[0.7-31.3]$} & 0.1 \\
\hline e France & 1 & 0.2 & {$[0.03-1.3]$} & 3.6 & {$[0.3-40.6]$} & 0.3 & 0.3 & {$[0.02-6.1]$} & 0.5 \\
\hline
\end{tabular}

Attendance of (during the previous year):

- Outdoor meeting places

$\begin{array}{lllllll}\text { yes } & 9 & 0.3 & {[0.1-0.7]} & 0.3 & {[0.1-1.1]} & 0.07 \\ \text { no } & 17 & 0.9 & {[0.4-2.1]} & \text { ref. } & & \end{array}$

- Use of gay websites or use of mobile-based GPS applications

\begin{tabular}{|c|c|c|c|c|c|c|c|c|c|}
\hline yes & 23 & 1.0 & {$[0.5-2.1]$} & 21.5 & {$[4.7-98.4]$} & $<0.001$ & 5.2 & {$[1.0-27.9]$} & $<0.05$ \\
\hline no & 3 & 0.05 & {$[0.01-0.2]$} & ref. & & & ref. & & \\
\hline \multicolumn{10}{|c|}{ JAI with casual partners (during the previous year) } \\
\hline yes & 25 & 1.7 & {$[0.8-3.4]$} & 14.3 & {$[5.0-337.6]$} & 0.001 & 11.0 & {$[1.3-95.0]$} & 0.03 \\
\hline no & 1 & 0.04 & {$[0.006-0.3]$} & ref. & & & ref. & & \\
\hline \multicolumn{10}{|c|}{ More than 10 sexual partners (during the previous year) } \\
\hline yes & 22 & 1.4 & {$[0.6-3.1]$} & 10.0 & {$[2.3-44.0]$} & 0.002 & 3.6 & {$[1.1-12.3]$} & 0.04 \\
\hline n & 4 & 0.1 & {$[0.04-0.5]$} & ref. & & & ref. & & \\
\hline
\end{tabular}

At least one STI (during the previous year)

$\begin{array}{lllllll}\text { yes } & 15 & 1.7 & {[0.8-3.4]} & 3.2 & {[0.8-13.1]} & 0.1 \\ \text { no } & 11 & 0.5 & {[0.2-1.6]} & \text { ref. } & & \end{array}$

Consumption of (before or during sexual intercourse, during the previous year)

- Alcohol (more than 6 glasses per day)

\begin{tabular}{|c|c|c|c|c|c|c|c|c|c|}
\hline yes & 16 & 0.4 & {$[0.2-0.8]$} & 0.3 & {$[0.08-1.0]$} & 0.05 & 0.3 & {$[0.1-0.8]$} & 0.02 \\
\hline no & 10 & 1.2 & {$[0.4-3.2]$} & ref. & & & ref. & & \\
\hline \multicolumn{10}{|l|}{ Chemsex (during the previous year) } \\
\hline yes & 20 & 3.5 & {$[1.8-6.7]$} & 11.3 & {$[1.9-68.2]$} & 0.008 & 3.8 & {$[1.1-12.6]$} & 0.03 \\
\hline no & 6 & 0.3 & {$[0.06-1.6]$} & ref. & & & ref. & & \\
\hline \multicolumn{10}{|l|}{ lamming (lifetime) } \\
\hline yes, without sharing of injection equipment & 10 & 9.4 & {$[3.3-24.1]$} & 23.2 & {$[5.0-109]$} & $<0.001$ & 6.0 & {$[1.6-23.3]$} & 0.009 \\
\hline yes and sharing of injection equipment & 3 & 16.6 & {$[3.5-52.6]$} & 41.2 & [6.2-271] & $<0.001$ & 3.8 & [1.5-9.7] & 0.006 \\
\hline $\mathrm{No}$ & 13 & 0.4 & {$[0.1-1.3]$} & ref. & & & ref. & & \\
\hline
\end{tabular}


Table 2 Characteristics of chronic HCV-infected MSM and associated factors, Prevagay 2015, France - weighted data (Continued)

\begin{tabular}{|c|c|c|c|c|c|c|c|c|c|}
\hline & \multicolumn{3}{|c|}{ Prevalence $^{\mathrm{a})}$} & \multicolumn{3}{|c|}{ Univariate analysis } & \multicolumn{3}{|c|}{ Multivariable analysis } \\
\hline & $n$ & $\%$ & [Cl95\%] & $\mathrm{PR}$ & [Cl95\%] & $\mathrm{p}$ & PRa & [Cl95\%] & $\mathrm{p}$ \\
\hline \multicolumn{10}{|c|}{ Practices with casual partners (during the previous year) } \\
\hline \multicolumn{10}{|l|}{- BDSM } \\
\hline yes & 11 & 1.5 & {$[0.6-3.7]$} & 2.5 & {$[0.7-9.0]$} & 0.1 & & & \\
\hline no & 15 & 0.6 & {$[0.2-1.5]$} & ref. & & & & & \\
\hline \multicolumn{10}{|l|}{ - Fisting } \\
\hline yes & 16 & 2.9 & {$[1.1-7.7]$} & 10.8 & {$[2.7-42.9]$} & 0.001 & 5.3 & {$[2.0-14.0]$} & 0.001 \\
\hline no & 10 & 0.3 & {$[0.1-0.7]$} & ref. & & & ref. & & \\
\hline \multicolumn{10}{|l|}{ HIV status ${ }^{b)}$} \\
\hline HIV + diagnosed & 20 & 3.2 & {$[1.6-6.3]$} & 9.6 & {$[1.8-52.2]$} & 0.009 & 4.5 & {$[1.1-18.5]$} & 0.04 \\
\hline HIV + undiagnosed & 1 & 0.2 & {$[0.03-1.5]$} & 0.6 & {$[0.05-7.5]$} & 0.7 & 0.3 & {$[0.01-6.6]$} & 0.5 \\
\hline HIV - & 5 & 0.3 & {$[0.1-1.6]$} & ref & & & ref. & & \\
\hline \multicolumn{10}{|c|}{ Screening for hepatitis C (previous year) } \\
\hline yes & 12 & 0.3 & {$[0.1-0.7]$} & 0.3 & {$[1.0-1.0]$} & 0.06 & 0.2 & {$[0.5-0.6]$} & 0.006 \\
\hline no or did not know & 14 & 1.0 & {$[0.4-2.4]$} & ref & & & ref. & & \\
\hline
\end{tabular}

year had been screened. This percentage was $61.2 \%$ [52.7-69.1] among HIV-infected MSM aware of their HIV status, 64.3\% [58.1-70.1] among those reporting at least one STI, and 54.8\% [46.9-62.5] among those who reported fisting (Table 3 ).

In the multivariable analysis (Table 3 ), HCV screening during the previous year was significantly more frequent in MSM who reported (during the previous year) more than 10 sexual partners $(\mathrm{PRa}=1.2[1.0-1.4], p=0.01)$, at least one STI $(\mathrm{PRa}=1.4[1.2-1.6], p<0.001)$ and fisting $(\mathrm{PRa}=1.3[1.1-1.5], p=0.004)$. It was also significantly more frequent in HIV-infected MSM aware of their HIV status $(\mathrm{PRa}=1.4$ [1.2-1.6], $p=0.001)$. HCV screening was lower among MSM over 30 years of age (30-44 years: $\mathrm{PRa}=0.8[0.7-1.0], p=0.017 ; 45$ years and older: $\mathrm{PRa}=0.7[0.6-0.8], p<0.001)$, in those who did not know whether they were vaccinated against hepatitis $B$ $(\mathrm{PRa}=0.6[0.4-0.8], p<0.001)$, in those who were not vaccinated against meningococcus $C$ ( $\mathrm{PRa}=0.6$ [0.5-0.8], $p<0.001)$, and in those who did not know whether they were vaccinated against meningococcus $\mathrm{C}(\mathrm{PRa}=0.7$ [0.6-0.8], $p<0.001)$. HCV screening was also lower in HIV-infected MSM not aware of their HIV status ( $\mathrm{PRa}=0.5$ [0.3-0.9], $p=0.03)$.

\section{Discussion}

Among chronically $\mathrm{HCV}$-infected MSM in our study, $60 \%$ were co-infected with HIV. HIV/HCV co-infection is a matter of great concern because people living with HIV not on treatment have higher HCV RNA levels and experience more rapid $\mathrm{HCV}$ disease progression than HIV-negative individuals [28, 29]. One systematic review estimated that the seroprevalence of $\mathrm{HIV} / \mathrm{HCV}$ (i.e., positive for $\mathrm{HCV}$ antibodies) co-infection at $6.4 \%$ (3.2-10.0) in MSM [30]. Another review estimated the range of prevalence of active $\mathrm{HCV}$ infection at between 5.3 and $7.3 \%$ in HIV-infected MSM and between 4.9 and $5.9 \%$ in non-injecting HIV-infected MSM [31]. Estimates from two previous international studies showed that the risk of $\mathrm{HCV}$ infection was four [5] to almost six times higher (odds ratio: 5.8 [4.5-7.4]) [30] in HIV-infected MSM than in their HIV-negative counterparts. In our study, prevalences were lower than these but were consistent with estimates in the United Kingdom [32]. Prevalence data are often difficult to compare because of differences in methodologies (recruitment of MSM, biological markers used (HCV RNA vs. HCV antibodies), matrices and collection support (capillary whole blood collected on DBS vs. venous whole blood in a tube)). HCV prevalences from MSM recruited in gay venues, which are places for socializing, cannot be compared with those produced from hospitalised patients, with cohorts of HIV-infected MSM or with MSM attending STI clinics.

The role of the sexual transmission of $\mathrm{HCV}$ identified in our study (UAI with casual partners, more than 10 sexual partners and fisting) has already been explored in the literature. HCV infections have been reported among MSM who do not report drug injection [33]. Risky sexual behaviours such as fisting and unprotected 
Table 3 Characteristics of MSM declaring screening for hepatitis C during the previous year and associated factors, Prevagay 2015, France - weighted data

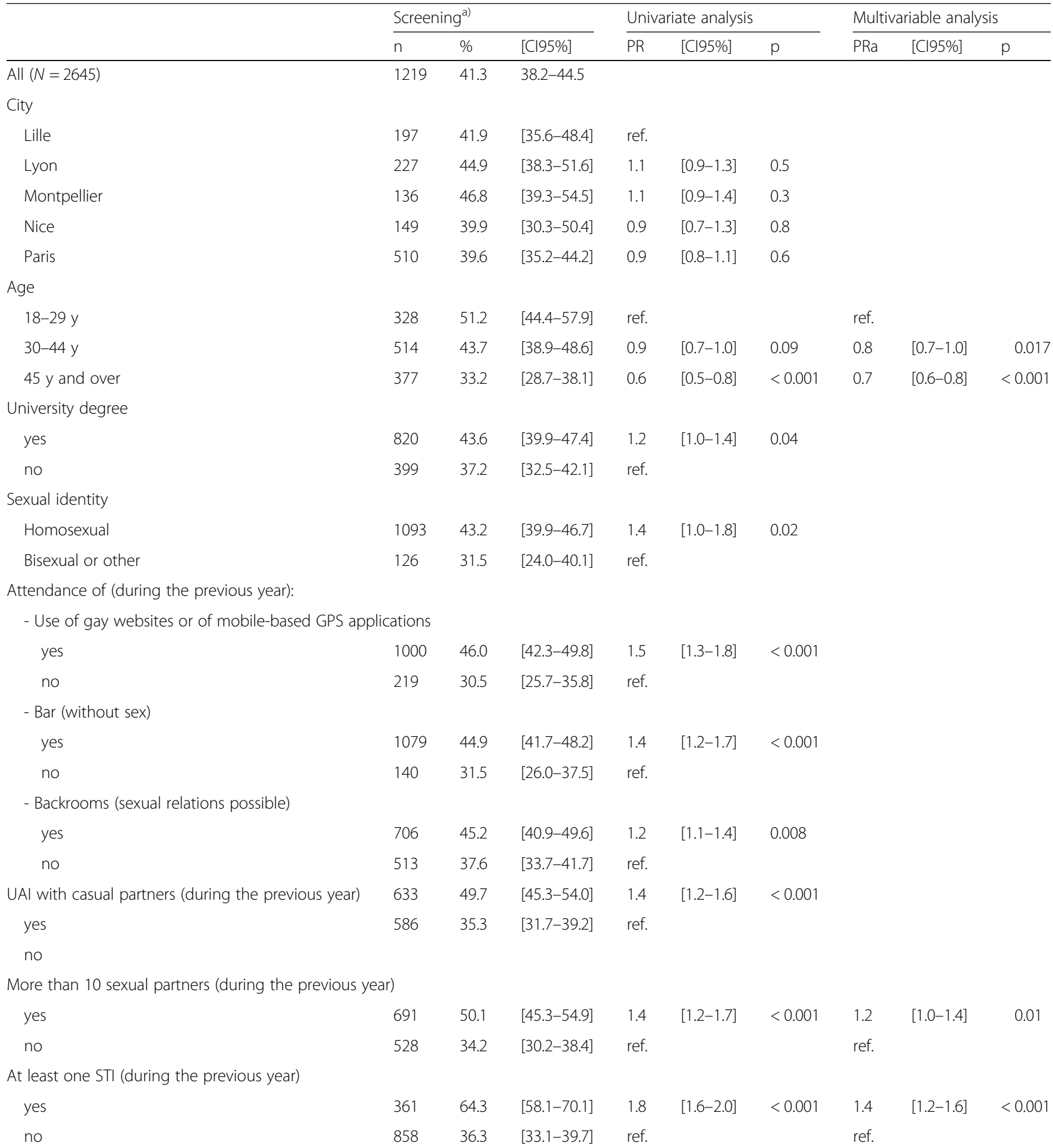

Consumption of (before or during sexual intercourse, during the previous year)

- Alcohol (more than 6 glasses per day)

$\begin{array}{lllllll}\text { yes } & 832 & 44.4 & {[40.7-48.2]} & 1.2 & {[1.0-1.4]} & 0.03 \\ \text { no } & 387 & 37.0 & {[32.1-42.2]} & & & \end{array}$

Chemsex (during the previous year) 
Table 3 Characteristics of MSM declaring screening for hepatitis C during the previous year and associated factors, Prevagay 2015, France - weighted data (Continued)

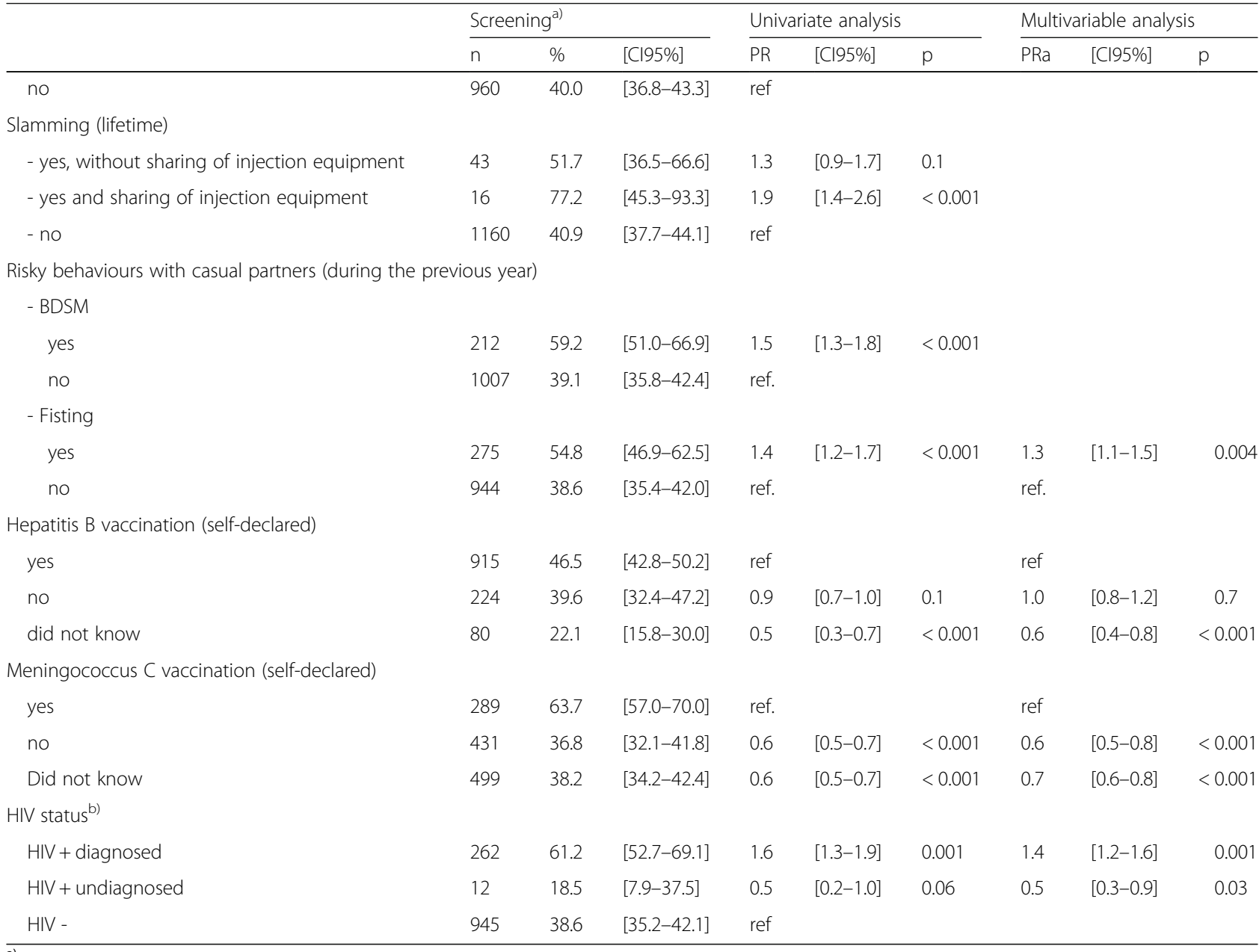

a) $\mathrm{n}$ and \%: crude number and weighted prevalence of MSM who declared screening for hepatitis $\mathrm{C}$ during the previous year in the reported category. For instance, 1093 MSM who defined themselves as homosexual reported HCV screening during the previous year; the prevalence of HCV screening during the previous year among the MSM who defined themselves as homosexual is estimated to be $43.2 \%$ [39.9-46.7]

b) undiagnosed HCV or HIV (MSM unaware of their HCV or HIV status): HCV or HIV status confirmed by virologic analysis after respondent reported "negative" or "not certain of being negative" or "I don't know" to the question on "status" in the self-administered questionnaire. Diagnosed HCV or HIV (MSM aware of their $\mathrm{HCV}$ or HIV status): HCV or HIV status confirmed by virologic analysis after respondent reported to be HIV or HCV positive in the self-administered questionnaire

intercourse can be mucosally traumatic and may be associated with bleeding. It has been suggested that they are also associated with the risk of contracting HCV [32, $34,35]$. Whether bleeding is necessary for HCV transmission is still debatable. Some studies have identified of $\mathrm{HCV}$ in seminal and rectal fluids of HIV infected men and providing evidence that these fluids can mediate HCV transmission [36, 37].

The higher risk among MSM who reported lifetime slamming (with or without sharing of injection materials) may mainly be due to the use of intravenous drugs. Indeed, the association between $\mathrm{HCV}$ infection and a history of IDU among MSM has already been widely described [33, 38]. Among drug users, anti-HCV antibody prevalence is high (44\% [CI95\%: 39.6-47.9] in France in 2011) [39]. In our study, reporting chemsex during the previous year, including the consumption of drugs by routes other than injection, was also significantly associated with a higher chronic HCV prevalence. Some studies have shown that chemsex is associated with unprotected anal sex, with sex with multiple partners and with increased STI rates [4]. One hypothesis is that risky sexual behaviours, associated with potential anal or rectal trauma resulting from longer and more intense sexual encounters under the influence of drugs, could facilitate HCV transmission among MSM.

The use of gay websites and/or mobile-based GPS applications to meet sexual partners are very popular with MSM [40]. In our study, almost $70 \%$ reported using them. The increased risk of infection and the evolution of meeting practices constitute major challenges in terms of prevention interventions for these population. 
Higher HCV prevalence among MSM born outside France may be partly explained by $\mathrm{HCV}$ prevalence in the country of birth (Africa or Asia) but also by the mobility of the gay community, particularly for festive events in European countries [41]. Special vigilance is needed for these MSM. The fact that alcohol consumption was associated with a reduced risk of chronic $\mathrm{HCV}$ infection may be partly explained by reduced consumption of alcohol in MSM injecting psychoactive products. The reasons why MSM living in medium-sized towns (from 20,000 to 100,000 inhabitants) had a higher risk of chronic HCV infection is difficult to explain. These results need to be confirmed in other studies. Bias cannot be excluded.

Recent data show a specific epidemiological evolution in MSM in France. Data from the Dat'AIDS cohort suggest that trends in $\mathrm{HCV}$ epidemiology in HIV-positive MSM differ from those observed in other HIV-positive populations. From 2012 to 2016, HCV incidence for first $\mathrm{HCV}$ infection increased from $0.35 / 100$ patient-years (PY) to $0.92 / 100 \mathrm{PY}$ in HIV-positive MSM $(p<0.001)$, while the incidence in non-MSM HIV-positive patients (with other risk factors) remained stable and close to $0.1 / 100$ PY. The incidence of $\mathrm{HCV}$ reinfection was higher in HIV-positive MSM than in other HIV-positive patients with the incidence remaining stable over time in both groups [42, 43].

Our results provide clues to a greater understanding of the factors associated with $\mathrm{HCV}$ infection among MSM in France, and consequently can inform future prevention measures to be adopted. Higher HCV prevalences in HIV-positive MSM and among those who reported multiple sexual partners underline the need to implement routine $\mathrm{HCV}$ screening in these populations. Screening should also be reinforced in MSM reporting mucosally-traumatic sexual practices, chemsex and lifetime slamming, as the risk of chronic HCV infection is significantly increased.

However, the low number of chronic HCV-infected MSM $(n=26)$ limits the power of our analysis. Indeed, the wide confidence intervals underline the need to be cautious about interpreting these data.

The very low number of identified HCV genotypes in our study limits the conclusions that can be drawn on circulating genotypes in this population. However, our results are consistent with those found for HIV-infected MSM in the French Dat'AIDS cohort study where incident cases were mainly infected with genotype 4 (53\%) followed with genotype 1A (39\%) [43].

Since 2013, several very effective, well-tolerated and safe DAA drugs have been approved worldwide $[10,11]$. DAA were made available in France in 2013 for the treatment of F3-F4 fibrosis patients. In 2016, French guidelines recommended treating all $\mathrm{HCV}$ infected patients irrespective of fibrosis stage [13]. The WHO's goal is to eliminate viral hepatitis worldwide by 2030 [9], while France hopes to do so by 2025 . In order to achieve this, screening is essential. HCV screening offers several potential benefits for infected persons. Patients testing positive can be promptly linked to care. Behavioural changes can be made by MSM aware of their HCV status to decrease the risk for transmission to others. Early identification and treatment are also important to limit transmission among MSM.

Only $41.3 \%$ of our study participants reported HCV screening during the previous year while $70 \%$ reported lifetime HCV screening. The latter value is close to that observed among MSM in Australia (68.1\%) [44] but higher than those reported in China in 2017 (41\%) and in the United States in 1999 (38.8\%) [45, 46]. Few studies to date have investigated $\mathrm{HCV}$ screening behaviours in MSM. The differences in recruitment (MSM recruited in gay venues vs. online surveys) make comparisons difficult. Since prevention messages are often disseminated in gay venues in France, it is possible that the MSM included in our study were more aware of prevention than MSM who do not frequent such venues. Consequently, the screening percentages estimated in our study may slightly overestimate those of the overall French MSM population.

European experts recommend that HIV-infected MSM at risk of contracting acute hepatitis $C$ infection should be screened for the disease annually $[14,15]$. Additional $\mathrm{HCV}$ testing is recommended in HIV-positive MSM who report HCV-related sexual risk behaviours (in particular BDSM practices) and in those diagnosed with other STI [47]. The American Association for the study of liver disease (AASLD) and the infectious Disease Society of American (IDSA) recommend annual HCV testing for sexually active HIV-positive MSM and more frequent testing based on the presence of high-risk sexual or drug use behaviours [16]. For HIV-negative MSM, $\mathrm{HCV}$ screening is recommended for MSM who report sexual risk behaviours, in particular those who are eligible for HIV Pre-Exposure Prophylaxis (PrEP) [16, 47]. French guidelines recommend HCV screening every 6 months in HIV-infected MSM, and HCV and HIV screenings every 3 months in high-risk MSM (including those practicing chemsex, those reported an STI in the previous year, those taking PrEP, and those reporting UAI with casual partners) [12]. Because HCV reinfection incidence is high among HIV-infected MSM [48], international experts recommend HCV screening in MSM with previous and resolved HCV infection [13, 16, 47].

In the present study, $\mathrm{HCV}$ screening was significantly more frequent in HIV-infected MSM aware of their HIV status which is in line with other studies [44, 45]. Reflecting current screening recommendations for 
specific populations, previous screening was also significantly higher among MSM reporting risk behaviours such as multiple sexual partners, fisting and at least one STI during the previous year. More frequent screening also highlights the awareness of some MSM of the potential for sexual transmission of HCV. In contrast, in Australia, specific sexual activities were not associated with a greater likelihood of HCV screening [44]. HCV screening is still inadequate in France, since almost 40\% of the HIV-infected MSM aware of their HIV status in our study had not been screened during the previous year. This rose to almost $50 \%$ in those who reported chemsex. Furthermore, less than $40 \%$ of chronic $\mathrm{HCV}$-infected MSM were aware of their HCV status.

$\mathrm{HCV}$ screening in older MSM in France is also currently inadequate. Specific prevention messages and educating physicians about the importance of $\mathrm{HCV}$ screening in this population are vital.

Our results also highlight the importance of comprehensive medical management of MSM, which couples the actions of screening with strategies of prevention. In our study, MSM not vaccinated against hepatitis B or meningococcal $\mathrm{C}$ were less likely to be screened for $\mathrm{HCV}$. These values were lower still among those who were unaware of their hepatitis $B$ vaccination status, and among HIV-infected MSM unaware of their infection. General practitioners have an important role in counselling and promoting prevention actions. Expanding accessible access irrespective of risk behaviours and risk awareness of MSM is essential. MSM more exposed to at-risk situations are more likely to attend health centres which offer both screening and vaccinations [49]. MSM with a lower risk perception are less likely to feel concerned by recommendations specific to MSM [17]. Special efforts are therefore needed to reach MSM further away from care, as they may constitute low-noise virus circulation sources.

The implementation of PrEP in France could be a real opportunity for $\mathrm{HCV}$ prevention in HIV-negative MSM and more particularly chemsexers [12]. PrEP offers comprehensive medical monitoring included vaccinations (hepatitis A and B) and frequent testing for STI and HCV.

The use of a sampling frame for the first time to investigate HCV, HBV and HIV prevalence in MSM attending gay venues constitutes the main strength of our study. More specifically, TLS associated with sampling weights which takes account probabilities of inclusion and frequencies venue attendance in inference is very important to provide the most accurate estimations possible for MSM attending gay venues $[50,51]$. Collaboration with the association ENIPSE was decisive in setting up this study. Thanks to ENIPSE's long history, we were able to identify gay venues and gain easier access to their managers with a view to inviting them to participate. The
MSM participation rate in our study was higher than or similar to those reported in other studies [21]. This may be partly explained by the fact that the investigators themselves belonged to the MSM community. Furthermore, all investigators were specifically trained to implement the survey.

The study has limitations. The use of DBS for HCV antibody detection may have led to a slight underestimation of HCV prevalence [52]. However, DBS are sensitive and specific enough to detect $\mathrm{HCV}$ antibodies by means of third EIA after extraction using a new cutoff ratio for interpretation [23, 53]. Although no commercial HCV RNA assay based on automated real-time polymerase chain reaction or transcription-mediated amplification has yet been approved for use with whole blood recovered from DBS, in an updated systematic review on HCV-RNA testing, pooled sensitivity and specificity values were 98\% [95-99\%] and 98\% [95-100\%] [53]. As only $\mathrm{HCV}$ antibody positive samples were tested for RNA, HCV antibody negative may have been missed for some very recent infections.

Among people who refused to participate, only $21 \%$ agreed to complete a refusal questionnaire. Accordingly, it was difficult to compare respondents with non-respondents. It is likely that only the most highly motivated men, for whom prevention is important, agreed to participate, and this most probably led to an underestimation of $\mathrm{HCV}$ prevalence and overestimation of $\mathrm{HCV}$ screening in our population [19].

We also need to be cautious when interpreting vaccination coverage and previous HCV screening. Self-reporting vaccination status may be associated with poor understanding and recall bias. Participants may also not correctly remember previous $\mathrm{HCV}$ screening (recall bias) or may not have been informed of previous screening by providers (ascertainment bias).

Finally, despite TLS being the current method of choice to conduct surveys among hard-to-reach populations such as MSM, our results cannot be extended to all the MSM population. Men recruited through TLS appeared more connected to the gay community than those recruited through internet sampling. The former also reported a greater number of sexual partners and less UAI with regular or casual partners [54].

\section{Conclusion}

Chronic HCV prevalence in MSM attending gay venues in 5 French metropolitan cities was low but was significantly greater in HIV-infected MSM and those with risky sexual behaviours including slamming, chemsex, fisting, multiple sexual partners and UAI with casual partners. Despite current French and international recommendations, $\mathrm{HCV}$ screening is inadequate in this population and needs to be improved, especially among 
HIV-infected MSM and other MSM most exposed to risk. A fuller understanding of the drivers of the epidemic and of HCV screening are needed to identify effective public health control strategies. Comprehensive medical management, which combines the actions of screening and linkage to care with prevention strategies is essential to control HCV among MSM.

\section{Abbreviations}

BDSM: Bondage, discipline, sadism and masochism; DBS: Dry blood spot; HBV: Hepatitis B virus; HCV: Hepatitis C virus; HIV: Human immunodeficiency virus; MSM: Men who have sex with men; NRL : National Reference Laboratory; Prep: HIV Pre-Exposure prophylaxis; PY: Patient-year; RNA: Ribonucleic acid; STI: Sexually transmitted infection; TLS: Time-location sampling; UAl: Unprotected anal intercourse

\section{Acknowledgements}

The PREVAGAY2015 group, composed of Annie Velter, Antonio Alexandre, Francis Barin, Stéphane Chevaliez, David Friboulet, Marie Jauffret-Roustide, Florence Lot, Nathalie Lydié, Gilles Peytavin, Olivier Robineau, Leila Saboni, Claire Sauvage, Cécile Sommen.

We would like to thank all those who agreed to participate in the PREVAGAY2015 study.

We also thank the employees of the association ENIPSE who carried out the study on the ground (Sébastien Cambau, Jérôme Derrien, Sylvain Guillet, Loïc Jourdan, Cyril Kaminski, Vivien Lugaz, Cedric Péjou, Erika Thomas Des Chenes, Florian Therond, Richard De Wever), and the associations that supported the study throughout, including AIDES (Vincent Coquelin), Act Up (Hugues Fisher), Le 190 (Michel Oyahon), Sidaction (Sandrine Fournier). Our thanks to Kevin Babaud, Céline Desouche and Damien Thierry for their excellent technical assistance, and Pascal Chaud, Agnès Lepoutre, Philippe Malfait, Bakhao Ndiaye, Cyril Rousseau, Christine Saura, Yassoungo Silue and Stephanie Vandentorren from regional units of Santé publique France for their region implication.

We would like to extend our warmest thanks to all the institutions that agreed to participate, and all the associations who facilitated the study.

\section{Funding}

The study was funded by Sante Publique France, ANRS (France REcherche Nord\&Sud Sida-hiv Hépatites), Sidaction and the following Regional Health Agency: Hauts de France, Auvergne-Rhône-Alpes, Occitanie, Provence-AlpesCôte d'Azur and Île-de-France.

The funders had no role in study design, data collection and analysis, interpretation of data, decision to publish, or preparation of the manuscript.

\section{Availability of data and materials}

The datasets used and/or analysed during the current study are available from the corresponding author on reasonable request.

\section{Authors' contributions}

SV analysed the data, completed statistical analysis, wrote the initial draft of the manuscript and provided critical revisions the manuscript. LS, CS1, CS2, FL made substantial contributions to data analysis. SC carried out the biological analyses for HCV and HBV. FB carried out the biological analyses for HIV. AA participate in the implementation of the study. AV designed the study, FL and MJR contributed to the protocol and the questionnaire conception. CS1 corresponding to Claire Sauvage, CS2 corresponding to Cécile Sommen. All authors reviewed the various drafts, read and approved the final manuscript.

\section{Ethics approval and consent to participate}

The study conformed to the ethical guidelines of the 1975 Helsinki Declaration. The study protocol was approved by a French ethical committee (reference number:2014-A01605-42, July 2015, Comité de protection des personnes, lle-de-France IX) and was explained to all men meeting the inclusion criteria. All those who agreed to participate in the survey had to provide written informed consent.

\section{Consent for publication}

Not applicable

\section{Competing interests}

The authors declare that they have no competing interests.

\section{Publisher's Note}

Springer Nature remains neutral with regard to jurisdictional claims in published maps and institutional affiliations.

\section{Author details}

${ }^{1}$ Department of Infectious Diseases - Santé publique France, French national public health agency, 12 rue du Val d'Osne, 94415 Saint-Maurice, Cedex, France. ${ }^{2}$ National Reference Center for Viral Hepatitis B, C and Delta, Department of Virology, Hôpital Henri Mondor, Université Paris-Est, Créteil, France. ${ }^{3}$ INSERM U955, Créteil, France. ${ }^{4}$ National Reference Center for HIV, Inserm U1259 \& University Hospital, Tours, France. ${ }^{5}$ Equipe Nationale d'Intervention en Prévention et Santé pour les Entreprises (ENIPSE), Paris, France. ${ }^{6}$ Cermes 3, Inserm U988, UMR CNRS 8211, EHESS, Paris Descartes University, Paris, France.

Received: 15 March 2019 Accepted: 29 March 2019 Published online: 11 April 2019

\section{References}

1. Bradshaw D, Matthews G, Danta M. Sexually transmitted hepatitis C infection: the new epidemic in MSM? Curr Opin Infect Dis. 2013;26(1):66-72.

2. Hagan $\mathrm{H}$, Jordan $\mathrm{AE}$, Neurer J, Cleland CM. Incidence of sexually transmitted hepatitis C virus infection in HIV-positive men who have sex with men. AIDS. 2015;29(17):2335-45.

3. van de Laar T, Pybus O, Bruisten S, Brown D, Nelson M, Bhagani S, et al. Evidence of a large, international network of HCV transmission in HIV-positive men who have sex with men. Gastroenterology. 2009;136(5):1609-17.

4. Lockart I, Matthews GV, Danta M. Sexually transmitted hepatitis C infection: the evolving epidemic in HIV-positive and HIV-negative MSM. Curr Opin Infect Dis. 2019;32(1):31-7.

5. Yaphe S, Bozinoff N, Kyle R, Shivkumar S, Pai NP, Klein M. Incidence of acute hepatitis $C$ virus infection among men who have sex with men with and without HIV infection: a systematic review. Sex Transm Infect. 2012;88(7):558-64.

6. Meffre C, Le Strat Y, Delarocque-Astagneau E, Dubois F, Antona D, Lemasson JM, et al. Prevalence of hepatitis $B$ and hepatitis $C$ virus infections in France in 2004: social factors are important predictors after adjusting for known risk factors. J Med Virol. 2010;82(4):546-55.

7. Pioche C, Pelat C, Larsen C, Desenclos J-C, Jauffret-Roustide M, et al. Estimation of hepatitis $C$ prevalence in the general population, metropolitan France, 2011. Bull Epidemiol Hebd. 2016;(13-14:224-9 http://invs. santepubliquefrance.fr/beh/2016/13-14/2016 13-14_1.html.

8. Velter A, Barin F, Bouyssou A, Guinard J, Leon L, Le Vu S, et al. HIV prevalence and sexual risk behaviors associated with awareness of HIV status among men who have sex with men in Paris, France. AIDS Behav. 2013;17(4):1266-78.

9. WHO, World Health Organization. Global hepatitis report 2017, Geneva: World Health Organization; http://apps.who.int/iris/bitstream/handle/10665/ 255016/9789241565455-eng.pdf;jsessionid= E2D0796013167FC7FFA0295C58EF490D? sequence=1 (Accessed online on 4 April 2018). 2017.

10. Arends JE, Kracht PA, Hoepelman Al, European Study Group for Viral $\mathrm{H}$. Performance of hepatitis $\mathrm{C}$ virus (HCV) direct-acting antivirals in clinical trials and daily practice. Clin Microbiol Infect. 2016;22(10):846-52.

11. Suwanthawornkul T, Anothaisintawee T, Sobhonslidsuk A, Thakkinstian A, Teerawattananon Y. Efficacy of second generation direct-acting antiviral agents for treatment naive hepatitis C genotype 1: a systematic review and network meta-analysis. PLoS One. 2015;10(12):e0145953.

12. Conseil national du sida et des hépatites virales (CNS) and Agence nationale de recherche sur le Sida et les hépatites virales (ANRS). Guidelines for medical care for people living with HIV. Experts recommandations. Paris; https://cns.sante.fr/actualites/prise-en-charge-du-vih-recommandations-dugroupe-dexperts/ (Accessed online 6 Dec 2018). 2018.

13. Conseil national du sida et des hépatites virales (CNS) and Agence Nationale de recherche sur le sida et les hépatites virales (ANRS). Guidelines 
for medical care and follow up for people infected by HCV. Experts recommandations. 2016, Paris; https://solidarites-sante.gouv.fr/MG/pdf/ rapport_.pdf (Accessed online 6 december 2018).

14. European AIDS Clinical Society Guidelines v 8.1, 2016. www.eacsociety.org/ guidelines/eacs-guidelines/eacs-guidelines.html (Accessed online on 6 Dec 2018).

15. European ATNAHCICP. Acute hepatitis $\mathrm{C}$ in HIV-infected individuals: recommendations from the European AIDS treatment network (NEAT) consensus conference. AIDS. 2011;25(4):399-409.

16. Aasld-Idsa Hcv Guidance Panel. Hepatitis C guidance 2018 update: AASLDIDSA recommendations for testing, managing, and treating hepatitis $C$ virus infection. Clin Infect Dis. 2018;67(10):1477-92.

17. Velter A, Saboni L, Le Vu S, Lot F. HIV testing practices among men who have sex with men. Results of the gay and lesbian survey 2011, France. Bull Epidemiol Hebd. 2014;(32-33):541-7 http://invs.santepubliquefrance.fr//beh/ 2014/32-33/2014_32-33_2.html.

18. Vaux S, Chevaliez S, Saboni L, Sauvage C, Sommen C, Alexandre A, et al. Prevalence of hepatitis B virus (HBV) infection and vaccine coverage against $\mathrm{HBV}$ in men who have sex with men attending gay venues in five French cities. The PREVAGAY 2015 survey. Bull Epidémiol Hebd. 2018;(11):195-203 http://invs.santepubliquefrance.fr/beh/2018/11/2018_11_2.html.

19. Sommen C, Saboni L, Sauvage C, Alexandre A, Lot F, Barin F, et al. Time location sampling in men who have sex with men in the HIV context: the importance of taking into account sampling weights and frequency of venue attendance. Epidemiol Infect. 2018;146(7):913-9.

20. MacKellar DA, Gallagher KM, Finlayson T, Sanchez T, Lansky A, Sullivan PS. Surveillance of HIV risk and prevention behaviors of men who have sex with men--a national application of venue-based, time-space sampling. Public Health Rep. 2007;122(Suppl 1):39-47.

21. Holt M, Lea T, Asselin J, Hellard M, Prestage G, Wilson D, et al. The prevalence and correlates of undiagnosed HIV among Australian gay and bisexual men: results of a national, community-based, bio-behavioural survey. J Int AIDS Soc. 2015;18:20526.

22. Snowden JM, Chen YH, McFarland W, Raymond HF. Prevalence and characteristics of users of pre-exposure prophylaxis (PrEP) among men who have sex with men, San Francisco, 2014 in a cross-sectional survey: implications for disparities. Sex Transm Infect. 2017:93(1):52-5.

23. Soulier A, Poiteau L, Rosa I, Hezode C, Roudot-Thoraval F, Pawlotsky JM, et al. Dried blood spots: a tool to ensure broad access to hepatitis $C$ screening, diagnosis, and treatment monitoring. J Infect Dis. 2016;213(7):1087-95.

24. Bronowicki JP, Ouzan D, Asselah T, Desmorat H, Zarski JP, Foucher J, et al. Effect of ribavirin in genotype 1 patients with hepatitis $C$ responding to pegylated interferon alfa-2a plus ribavirin. Gastroenterology. 2006;131(4): $1040-8$

25. Le Vu S, Velter A, Meyer L, Peytavin G, Guinard J, Pillonel J, et al. Biomarkerbased HIV incidence in a community sample of men who have sex with men in Paris, France. PLoS One. 2012;7(6):e39872.

26. Deville J, Lavallée P. Indirect sampling: the foundations of the generalized weight share method. Surv Methodol. 2006;32:165-76.

27. Bourne A, Reid D, Hickson F, Torres-Rueda S, Weatherburn P. Illicit drug use in sexual settings ('chemsex') and HIV/STI transmission risk behaviour among gay men in South London: findings from a qualitative study. Sex Transm Infect. 2015;91(8):564-8.

28. Thein $\mathrm{HH}$, Yi Q, Dore GJ, Krahn MD. Natural history of hepatitis C virus infection in HIV-infected individuals and the impact of HIV in the era of highly active antiretroviral therapy: a meta-analysis. AIDS. 2008;22(15):1979-91.

29. Thomas DL, Astemborski J, Rai RM, Anania FA, Schaeffer M, Galai N, et al. The natural history of hepatitis $C$ virus infection: host, viral, and environmental factors. JAMA. 2000;284(4):450-6.

30. Platt L, Easterbrook P, Gower E, McDonald B, Sabin K, McGowan C, et al. Prevalence and burden of HCV co-infection in people living with HIV: a global systematic review and meta-analysis. Lancet Infect Dis. 2016;16(7):797-808.

31. Jordan AE, Perlman DC, Neurer J, Smith DJ, Des Jarlais DC, Hagan $H$. Prevalence of hepatitis $C$ virus infection among HIV+ men who have sex with men: a systematic review and meta-analysis. Int J STD AIDS. 2017;28(2):145-59.

32. Ireland G, Higgins S, Goorney B, Ward C, Ahmad S, Stewart C, et al. Evaluation of hepatitis $C$ testing in men who have sex with men, and associated risk behaviours, in Manchester, UK. Sex Transm Infect. 2017; 93(6):404-9.

33. van de Laar TJ, Matthews GV, Prins M, Danta M. Acute hepatitis C in HIVinfected men who have sex with men: an emerging sexually transmitted infection. AIDS. 2010;24(12):1799-812.
34. Larsen C, Chaix ML, Le Strat Y, Velter A, Gervais A, Auperin I, et al. Gaining greater insight into HCV emergence in HIV-infected men who have sex with men: the HEPAIG study. PLoS One. 2011;6(12):e29322.

35. Turner JM, Rider AT, Imrie J, Copas AJ, Edwards SG, Dodds JP, et al. Behavioural predictors of subsequent hepatitis $C$ diagnosis in a UK clinic sample of HIV positive men who have sex with men. Sex Transm Infect. 2006;82(4):298-300

36. Foster AL, Gaisa MM, Hijdra RM, Turner SS, Morey TJ, Jacobson KB, et al. Shedding of hepatitis $C$ virus into the rectum of HIV-infected men who have sex with men. Clin Infect Dis. 2017;64(3):284-8.

37. Turner SS, Gianella S, Yip MJ, van Seggelen WO, Gillies RD, Foster AL, et al. Shedding of hepatitis $\mathrm{C}$ virus in semen of human immunodeficiency virusinfected men. Open Forum Infect Dis. 2016:3(2):ofw057.

38. Midgard H, Weir A, Palmateer N, Lo Re V 3rd, Pineda JA, Macias J, et al. HCV epidemiology in high-risk groups and the risk of reinfection. J Hepatol. 2016;65(1 Suppl):S33-45.

39. Weill-Barillet $L$, Pillonel J, Semaille C, Leon L, Le Strat Y, Pascal $X$, et al. Hepatitis C virus and HIV seroprevalences, sociodemographic characteristics, behaviors and access to syringes among drug users, a comparison of geographical areas in France, ANRS-Coquelicot 2011 survey. Rev Epidemiol Sante Publique. 2016;64(4):301-12.

40. Grov C, Breslow AS, Newcomb ME, Rosenberger JG, Bauermeister JA. Gay and bisexual men's use of the internet: research from the 1990s through 2013. J Sex Res. 2014;51(4):390-409.

41. Vanden Berghe W, Nostlinger C, Hospers H, Laga M. International mobility, sexual behaviour and HIV-related characteristics of men who have sex with men residing in Belgium. BMC Public Health. 2013;13:968.

42. Pradat P, Huleux T, Raffi F, Delobel P, Valantin MA, Poizot-Martin I, et al. Incidence of new hepatitis C virus infection is still increasing in French MSM living with HIV. AIDS. 2018:32(8):1077-82.

43. Pradat P, Pugliese P, Poizot-Martin I, Valantin MA, Cuzin L, Reynes J, et al. Direct-acting antiviral treatment against hepatitis $C$ virus infection in HIVinfected patients - "En route for eradication"? J Inf Secur. 2017;75(3):234-41.

44. Brener L, Ellard J, Murphy D, Callander D. Perceptions and deflections: associations between attitudes towards people with hepatitis $\mathrm{C}$ and testing for hepatitis C among Australian gay and bisexual men. Sex Health. 2013; 10(3):268-74.

45. Fitzpatrick T, Pan SW, Tang W, Guo W, Tucker JD. HBV and HCV test uptake and correlates among men who have sex with men in China: a nationwide cross-sectional online survey. Sex Transm Infect. 2018;94(7):502-7.

46. Rhodes SD, Diclemente RJ, Yee LJ, Hergenrather KC. Factors associated with testing for hepatitis $C$ in an internet-recruited sample of men who have sex with men. Sex Transm Dis. 2001;28(9):515-20.

47. Brook G, Brockmeyer N, van de Laar T, Schellberg S, Winter AJ. 2017 European guideline for the screening, prevention and initial management of hepatitis B and C infections in sexual health settings. Int J STD AIDS. 2018;29(10):949-67.

48. Ingiliz P, Martin TC, Rodger A, Stellbrink HJ, Mauss S, Boesecke C, et al. HCV reinfection incidence and spontaneous clearance rates in HIV-positive men who have sex with men in Western Europe. J Hepatol. 2017;66(2):282-7.

49. Lorente N, Preau M, Vernay-Vaisse C, Mora M, Blanche J, Otis J, et al. Expanding access to non-medicalized community-based rapid testing to men who have sex with men: an urgent HIV prevention intervention (the ANRS-DRAG study). PLoS One. 2013;8(4):e61225.

50. Gustafson P, Gilbert M, Xia M, Michelow W, Robert W, Trussler T, et al. Impact of statistical adjustment for frequency of venue attendance in a venue-based survey of men who have sex with men. Am J Epidemiol. 2013; 177(10):1157-64

51. Leon L, Jauffret-Roustide M, Le Strat Y. Design-based inference in timelocation sampling. Biostatistics. 2015;16(3):565-79.

52. Chevaliez S, Pawlotsky JM. New virological tools for screening, diagnosis and monitoring of hepatitis B and C in resource-limited settings. J Hepatol. 2018:69(4):916-26.

53. Lange B, Roberts T, Cohn J, Greenman J, Camp J, Ishizaki A, et al. Diagnostic accuracy of detection and quantification of HBV-DNA and HCV-RNA using dried blood spot (DBS) samples - a systematic review and meta-analysis. BMC Infect Dis. 2017;17(Suppl 1):693.

54. Zablotska IB, Frankland A, Holt M, de Wit J, Brown G, Maycock B, et al. Methodological challenges in collecting social and behavioural data regarding the HIV epidemic among gay and other men who have sex with men in Australia. PLoS One. 2014;9(11):e113167. 